\title{
Arctic precipitation as represented in the NCEP/NGAR reanalysis
}

\author{
Mark C. Serreze, James A. Maslanik ${ }^{2}$ \\ ${ }^{1}$ Cooperative Institute for Research in Environmental Sciences, Division of Cryospheric and Polar Processes, \\ Campus Box 449, University of Colorado, Boulder, CO 80309-0449, U.S.A. \\ ${ }^{2}$ Colorado Center for Astrodynamics Research, Campus Box 431, University of Colorado, Boulder, CO 80309-0431, U.S.A.
}

\begin{abstract}
Arctic precipitation as depicted in the National Center for Environmental Prediction (NCEP) and the National Center for Atmospheric Research (NCAR) reanalysis effort is evaluated using 6 hourly model output for the period 1986-93 in conjunction with gauge-corrected climatologies. Climatological fields from the model agree favorably with observations in terms of general spatio-temporal patterns, but with some notable differences. In particular, the precipitation maximum over the central Arctic (the region north of $70^{\circ} \mathrm{N}$ ) is depicted in July, one month too early. Values are too low from August through December, resulting in underestimates of annual precipitation of about $40 \mathrm{~mm}$. Despite these shortcomings, the modeled precipitation fields appear to be sufficiently realistic to represent a base for blending with other data to provide gridded fields suitable for use in climate studies and sea-ice models.
\end{abstract}

\section{INTRODUCTION}

The Arctic sea-ice cover requires maintenance of a low-salinity surface layer. Surface runoff provides the largest singleocean fresh-water source of about $35 \mathrm{~cm} \mathrm{a}^{-1}$ (Aagaard and Carmack, 1989; Ivanov and Yankina, 1991). Following freshwater import through the Bering Strait, precipitation less evaporation $(P-E)$ over the Arctic Ocean itself provides the next largest contribution of $16-17 \mathrm{~cm} \mathrm{a}^{-1}$ (Serreze and others, 1995). Changes in precipitation over watersheds draining into the Arctic Ocean and over the Arctic Ocean itself may impact on sea-ice thickness and ice area, influencing ocean-to-atmosphere heat and moisture fluxes and, potentially, cloud cover and cyclone activity. The flux of sea ice through Fram Strait and the Canadian Arctic Archipelago influences the oceanic convective regime, impacting on the global thermohaline circulation (Zaucker and others, 1994). Arctic marine life is organized into complex food webs, conditioned by sea ice, nutrient availability and water density. Changes in these factors may impact on marine ecosystems and the biochemical cycling of essential nutrients. Changes in the terrestrial hydrologic cycle may also alter soil moisture, influencing plant communities and their grazers. Arctic soils and peatlands serve as sources and sinks of atmospheric trace gases, and appear to respond sensitively to changes in soil moisture and temperature (McCauley and Meier, 1991).

Addressing these issues requires improved databases of precipitation for model input and validation, as well as for diagnostic climate studies. Precipitation data from Arctic land stations (Vose and others, 1992) suffer from severe under catchment in areas of blowing snow (Woo and others, 1983). Even in summer, estimates may be low due to neglect of occult precipitation (fog, dew) over tundra areas (Dingman and others, 1980), trace values and wetting losses. As most Arctic stations are at low altitudes, the tendency for precipitation to increase with elevation also implies an underestimate of regional averages when station data are used. It is possible to adjust station data for exposure, winds and gauge type, but the network is still relatively sparse. Databases for the Arctic Ocean are primarily for long-term mean annual and monthly values (e.g. Bryazgin, 1976; Gorshkov, 1983; Legates and Wilmott, 1990). Aerological analyses using the reasonably dense network of Arctic rawinsonde stations can provide estimates of $P-E$, but only large areal averages can be obtained.

\section{MODELED PRECIPITATION FIELDS}

Recognition of the need for gridded fields of Arctic precipitation has led to interest in the evaluation of output from numerical weather prediction (NWP) models (WCRP, 1994). Although data assimilation/forecast systems vary between different NWP centers, the general procedure is to start with a previous forecast as a first "guess" of present atmospheric conditions. Observed data (e.g. from rawinsondes, dropsondes and satellites) are assimilated to adjust the forecast fields, providing analyses representing the best estimate of the current true state of the atmosphere, used to produce the next forecast. Assimilation data are primarily free-atmosphere variables. Archived fields represent a blend of analyses based on the first guess and assimilation (e.g. pressure heights), and modeled surface variables, including precipitation.

Modeled surface fields for the Arctic have suffered from a number of problems. These include the scarcity of sounding data over the central Arctic Basin, difficulties in quality control and in determining the appropriate weights for observations vs first-guess fields over such data-sparse areas, uncertainties in satellite-derived soundings, simplistic repre- 
sentation of sea ice (generally taken as a slab with fixed thickness and $100 \%$ concentration), inadequate physical parameterizations (particularly with respect to clouds), radiation and boundary-layer processes, and problems with filtering fields at the northernmost rows of gridpoint models. A further problem is a lack of temporal consistency in archived fields due to changes introduced in models and data assimilation systems (WCRP, 1994).

Limited cases studies of operational NWP output for recent years are nevertheless encouraging. Precipitation fields for April 1993 from a regional model of the Canadian Atmospheric Environment Service showed very good agreement with observations (Environment Canada, 1993). In a recent WCRP Arctic Climate System (ACSYS) workshop (held September 1995), it was demonstrated that precipitation fields from United Kingdom Meteorological Office (UKMO) and European Center for Medium-Range Weather Forecasts (ECMWF) models provide realistic spatio-temporal patterns in qualitative agreement with existing climatologies (H. Cattle, personal communication, 1995).

"Reanalysis" projects underway at several agencies are providing internally consistent gridded fields. Although still prone to many of the problems outlined above, including simplistic treatments of sea ice, they should provide improved archived fields through: 1) the elimination of temporal discontinuities through the use of "frozen" state-of-the-art data assimilation/forecast systems; and 2) the assurance that all available historical data are used in the assimilations, and are subjected to strict quality control. The most comprehensive of these projects represents a cooperative effort between the National Center for Environmental Prediction (NCEP formerly the National Meteorological Center) and the National Center for Atmospheric Research (NCAR). The NCEP/NCAR project aimed to complete the reanalysis for a 40 year time period (1957-96) by the end of 1996. Details of the reanalysis system are provided by Kalnay and others (1996).

The quality of reanalysis precipitation fields remains largely untested for the Arctic. A case study using NCEP/ NCAR output over the Mackenzie watershed for 1985 and 1986 (J. Walsh, personal communication, 1995 shows the seasonal cycles and spatial patterns of precipitation to be realistic, but with the model totals greater than from uncorrected station data. As station values are considered to be underestimates, this difference is in the "correct" direction. However, the largest discrepancies occur during spring and summer, when most precipitation would be in the liquid form. Precipitation patterns over Greenland and Antarctica, examined using 6 years of ECMWF reanalysis data, appear realistic (Genthon and Braun, 1995).

Here, we provide an initial evaluation of Arctic precipitation as depicted in the NCEP/NCAR reanalysis over the 8 year period 1986-93 for the region north of $60^{\circ} \mathrm{N}$. We use the 6 hourly instantaneous precipitation rates (in $\mathrm{kg} \mathrm{m}^{-2} \mathrm{~s}^{-1}$ ), which are provided over a $192 \times 94$ gaussian grid. The instantaneous rates were converted into monthly precipitation totals by month and year. Comparisons are made with several gauge-corrected climatologies, including the map of annual totals provided by Bryazgin (1976), based on data from fixed stations, aircraft landings and the Russian North Pole series of manned drifting camps (1916-74). We also use monthly means north of $70^{\circ} \mathrm{N}$ based on the Gorshkov (1983) atlas, which according to Burova (1983), rely on Bryazgin's (1976) results, as well as a recently acquired set of gauge- corrected monthly maps by Bryazgin (1976), updated using data through 1990.

\section{RESULTS}

\section{Annual field}

Figure 1 shows the spatial distribution of modeled annual precipitation averaged over the 8 years while Figure 2 provides the annual gauge-corrected map of Bryazgin (1976). The reanalysis fields were interpolated to the NMC octagonal grid using Cressman weights with a $500 \mathrm{~km}$ sphere of influence. This smoothing eliminates local "bull's-eyes" in precipitation that appear to result from spectral truncation errors. The model depicts the highest totals over the Atlantic side of the Arctic. Maximum values are found off the southeast coast of Greenland $(1400 \mathrm{~mm})$, with amounts decreasing to the northeast. This pattern is physically consistent with the effects of the frequent cyclone activity associated with the mean Icelandic Low, and the poleward decay of the North Atlantic cyclone track (Serreze, 1995). High totals (up to $1200 \mathrm{~mm}$ ) are also depicted near the edge of the map over southern Alaska, which reflects the influence of the Aleutian Low and orography. The lowest values (150$200 \mathrm{~mm}$ ) are found over the Beaufort Sea, parts of the Canadian Arctic Archipelago, the East Siberian Sea and northern Greenland. These are regions of infrequent cyclone activity for most of the year, and where anticyclonic conditions are common during winter and spring (Serreze and others, 1993).

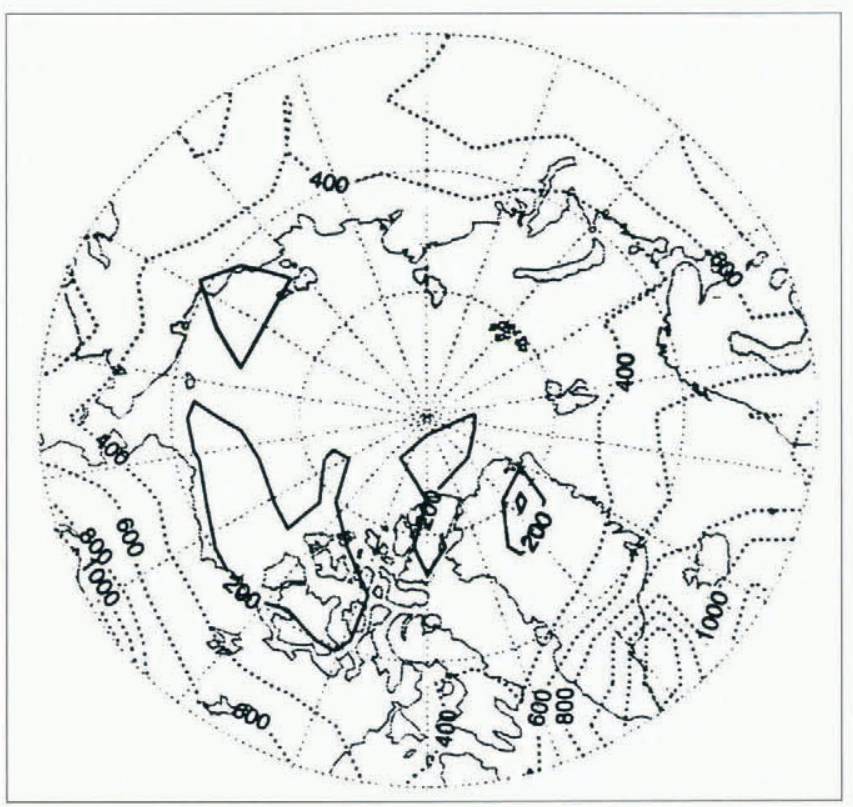

Fig. 1. Mean annual precipitation (1986-93) from the NCEP/NCAR reanalysis (in $\mathrm{mm}$ ).

Although the Bryazgin (1976) climatology is based on data from a different period and the gauge corrections employed are not well documented, comparisons indicate that the model is capturing the major spatial patterns of precipitation reasonably well. In particular, the model correctly depicts precipitation maxima over the Atlantic side of the Arctic and southern Alaska, and low central Arctic values. Nevertheless, there are some notable differences. In particular, Bryazgin (1976) shows high precipitation values $(>400 \mathrm{~mm})$ along the Atlantic side of the Arctic penetrating as far as Novaya Zemlya. The model also fails to capture 


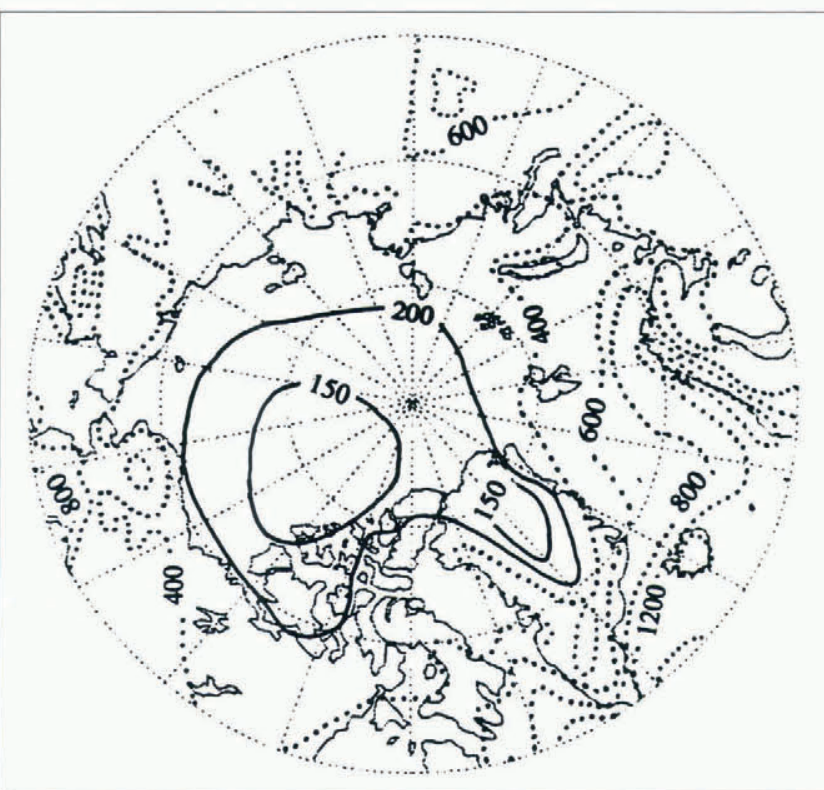

Fig. 2. Mean annual gauge-corrected precipitation (1916-74) redrawn after Bryazgin (1976) (in mm).

precipitation maxima related to local orography, such as along the Scandinavian coast, as well as over Iceland, Svalbard and Novaya Zemlya. This is likely to be related to the relatively low (T62) model resolution, as well as to the smoothing employed here. Nevertheless, these initial results must be considered encouraging.

\section{Seasonality and inter-annual variability}

Figure 3 shows the modeled average precipitation fields for January and July. The January pattern (Fig. 3a) is similar to that for the annual field, with the highest totals over the Atlantic side (up to $200 \mathrm{~mm}$ near the position of the Icelandic Low) and southern Alaska. By contrast, July (Fig. 3b) shows a reduction in Atlantic-side precipitation, coupled with increases over the central Arctic Ocean, Eurasia, central Alaska and Canada. These results are consistent with seasonal changes in atmospheric circulation (Whittaker and Horn, 1984; Serreze and others, 1993; Serreze, 1995).

During January, the primary North Atlantic cyclone track and the Icelandic and Aleutian Lows are strong, with the affected areas receiving relatively abundant precipitation. During summer, the North Atlantic track and subpolar lows weaken, but with cyclone activity becoming common over northern Eurasia, Canada and Alaska. Eurasian systems in particular tend to migrate into the central Arctic Ocean, where they subsequently occlude. While lows may enter the Arctic Ocean from anywhere along the Eurasian coast, a Laptev Sea track is preferred.

Bryazgin's (1976) updated monthly analyses agree with the model in showing a January precipitation of $10-20 \mathrm{~mm}$ over the central Arctic Ocean increasing towards the Atlantic side, but again display higher values along the Scandinavian coast. Bryazgin's (1976) data also show a reduction in July precipitation over the Atlantic side, with increases over the central Arctic Ocean, but with lower amounts $(30 \mathrm{~mm})$ than in the reanalysis $(30-40 \mathrm{~mm})$. Bryazgin's maps also display sharp increases over land, especially the local maxima over Alaska and eastern Eurasia, which are regions of frequent summertime cyclogenesis (Serreze, 1995).

The spatial pattern of the month of the precipitation maximum (Fig. 4), calculated for each NMC gridpoint from
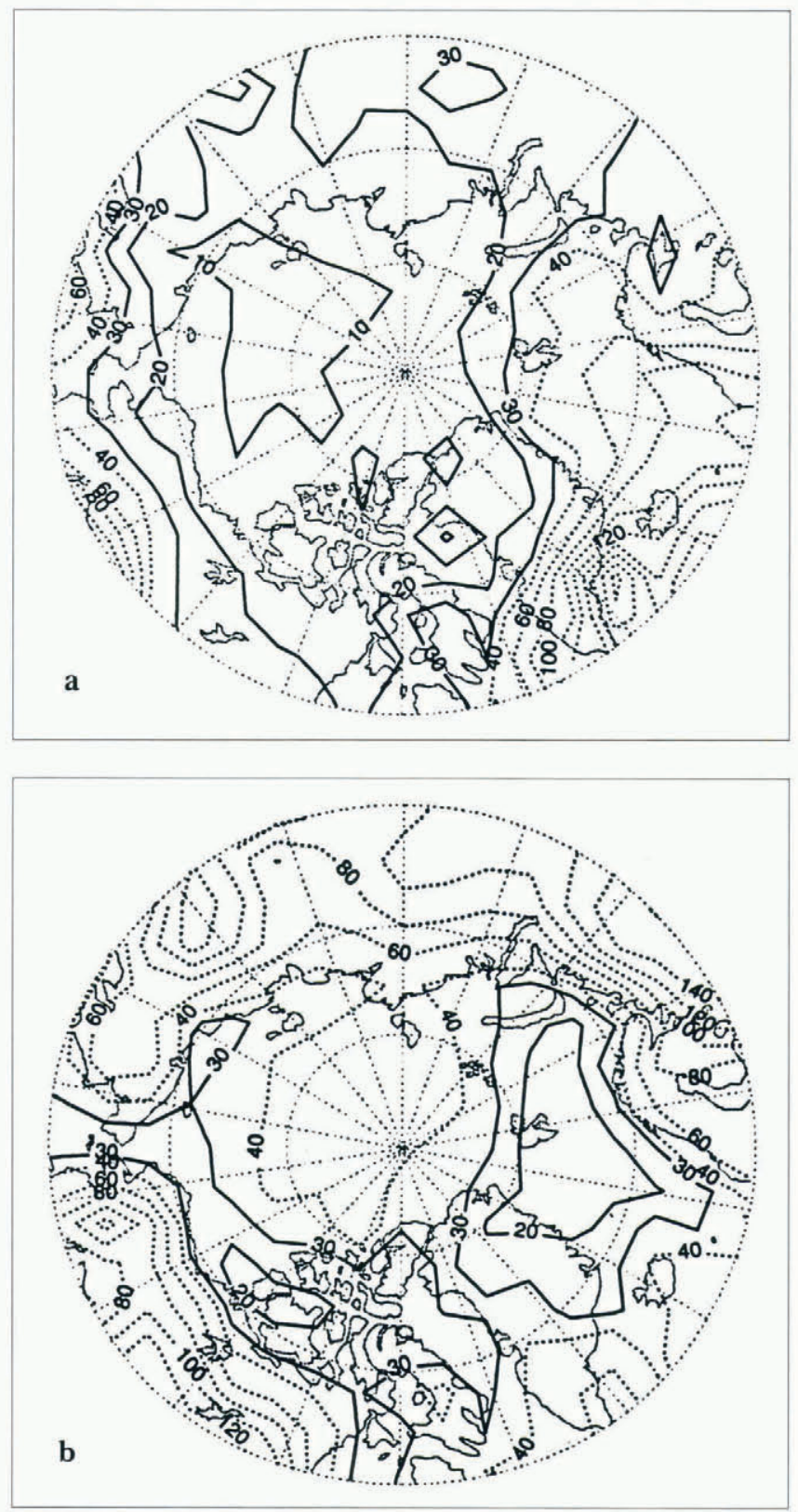

Fig. 3. Mean precipitation (1986-93) from the NCEP/

NCAR reanalysis (in $\mathrm{mm}$ ) for (a) January and (b) July.

the long-term monthly means, shows two major features: 1) an October-January maximum over the Atlantic side of the Arctic and the Baffin Bay/Davis Strait region; and 2) a June-September maximum over the remainder of the Arctic, with a spatially homogeneous July peak for the central Arctic Ocean. A recent analysis (Clark and others, 1996) of precipitation frequencies over the Arctic Ocean and its peripheral seas, evaluated from present weather reports contained in the Comprehensive Ocean Atmosphere Dataset (COADS) (Woodruff and others, 1987), shows this Atlantic-side winter maximum clearly. The timing of this maximum also agrees with the updated monthly maps of Bryazgin (1976). However, it appears that the model's July peak precipitation over the central Arctic Ocean is in error by at least a month.

This is illustrated in Figure 5, which shows the long-term (1986-93) monthly reanalysis precipitation averaged for the central Arctic, taken as the region north of $70^{\circ} \mathrm{N}$, the maximum and minimum values based on individual years, and the climatological monthly means from Gorshkov (1983). From January through April, the reanalysis means are low, but high from May through July. Despite these differences, 


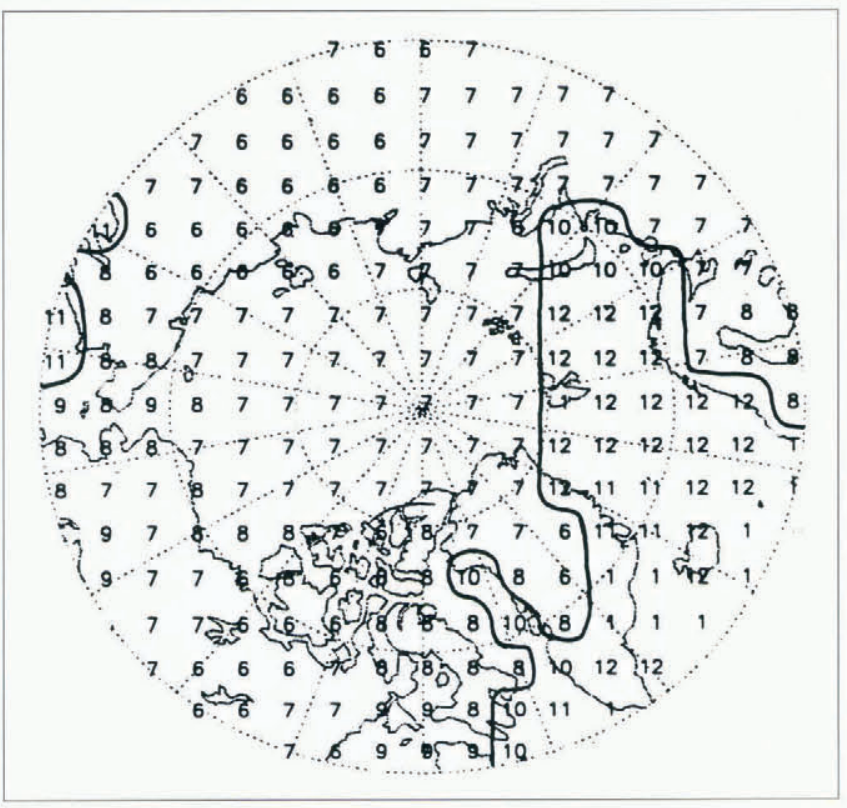

Fig. 4. Month of the precipitation maximum from the NCEP/ NCAR reanalysis, based on long-term (1986-93) monthly means. The solid line separates regions with October-January and June-September maxima.

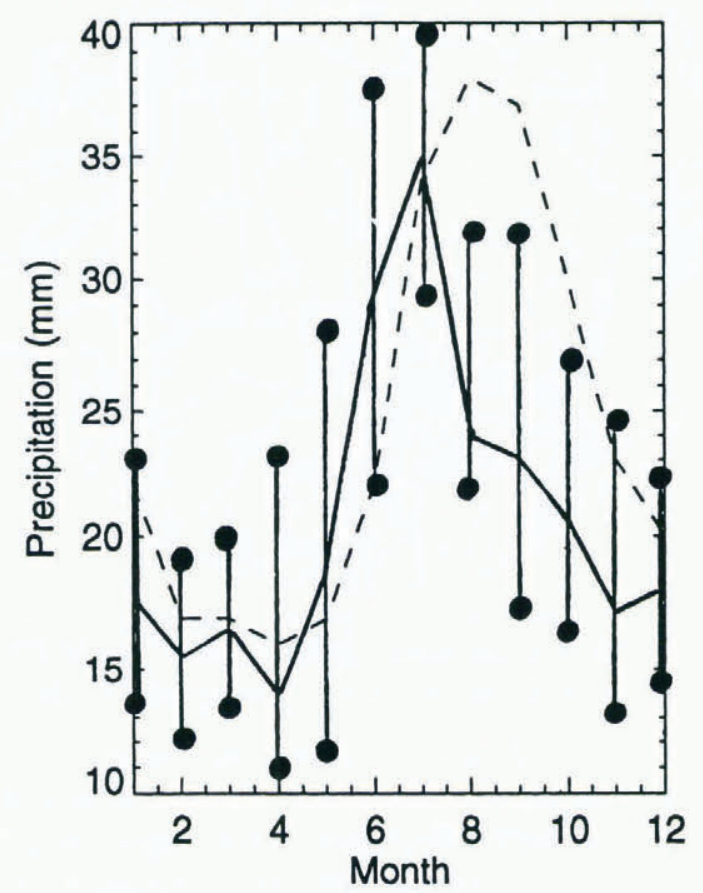

Fig. 5. Mean monthly precipitation for the region north of $70^{\circ} \mathrm{N}$ as depicted by Gorshkov (1983) (dashed line) and in the NCEP/NCAR reanalysis (solid line). The range in the reanalysis values over the 1986-93 is shown by the vertical lines ended by dots (all values in $\mathrm{mm}$ ).

the January-July reanalysis totals can be considered quite reasonable. However, the model shows a very sharp precipitation peak in July, a month earlier than shown the data presented by Gorshkov (1983), remaining far below his values through December. Even the positive extremes of the reanalysis precipitation are lower than the Gorshkov means from August through October. As shown in the monthly time series of modeled precipitation (Fig. 6), this July peak is persistent from year to year. Due largely to the underestimates from August through December, the model's annual-precipitation total for the central Arctic region is $250 \mathrm{~mm}$, as compared to $293 \mathrm{~mm}$ from the Gorshkov atlas. Interestingly,

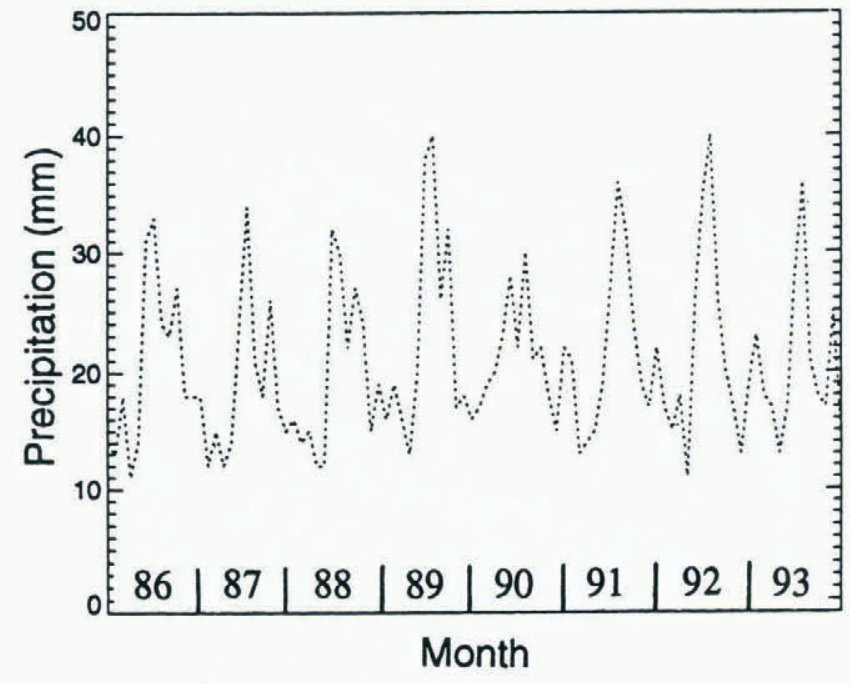

Fig. 6. Time series of monthly precipitation for the period 1986-93 from the NCEP/NCAR reanalysis for the region north of $70^{\circ} \mathrm{N}$ (in $\mathrm{mm}$ ).

nearly all models reviewed as part of the Atmospheric Model Intercomparison Project (AMIP) display an August precipitation maximum for the central Arctic (Kattsov and others, in press). Note also that the August peak depicted by these models occurs a month earlier than the September peak in the water vapor flux convergence and $P-E$ for the region north of $70^{\circ} \mathrm{N}$ as analyzed from rawinsonde data (Serreze and others, 1995).

\section{DISCUSSION}

Based on our initial study, the performance of the NCEP/ NCAR reanalysis to depict Arctic precipitation could perhaps best be described as uneven. The spatial patterns of long-term annual and monthly precipitation agree reasonably well with available climatologies, although there are some notable differences. In particular, the annual peak in precipitation over the central Arctic Ocean occurs too early in July with large underestimates from August through December. We recognize the possibility that the 8 years (1986-93) examined here might not be sufficiently long enough for effective comparisons with observed climatologies or the AMIP outputs, which span the period 1979-88 (Kattsov and others, in press).

The past decade has been anomalous in terms of Arctic circulation (Maslanik and others, 1996; Walsh and others, 1996). However, this period has been characterized by sharp increases in cyclone activity and accompanying reductions in sea-level pressure over the central Arctic Ocean, which, $a$ priori, suggest that precipitation over the central Arctic has recently been above normal. Resolving this issue will require further investigations using additional reanalysis data, as well as efforts to assess the model's treatment of high-latitude hydrologic processes.

Despite the shortcoming in the modeled fields, we echo the recommendations of the WCRP (WCRP, 1994) to examine methods of blending the reanalysis precipitation fields with observed data. Efforts are underway by C. Willmott at the University of Delaware to compute monthly gauge-corrected precipitation fields for Arctic land areas, building on techniques outlined by Legates and Wilmott (1990). Using such fields, along with the updated climatological monthly 
means from Bryazgin for the Arctic Ocean, and gaugecorrected station data, techniques such as optimal interpolation could be applied to obtain gridded fields for use in climate studies and sea-ice models.

\section{AGKNOWLEDGEMENTS}

This study was supported by NSF grants ATM-9315351, OPP-9504201 and OPP-9614297.

\section{REFERENCES}

Aagaard, K. and E. C. Carmack. 1989. The role of sea ice and other fresh water in the Arctic circulation. 7. Geophys. Res., 94 (Cl0), 14,485-14,498.

Bryazgin, N. N. 1976. Srednegodovoe kolichestvo osadkov v Arktike s uchetom pogreshnosti osadkomerov [Mean annual precipitation in the Arctic with consideration of gauge biases]. Tr. Arkt. Antarkt. Nauchno-Issled. Inst. $323,40-74$.

Burova, L. P. 1983. Vlagooborot v atmosfere Arktiki / Moisture exchange in the Arctic atmosphere. Leningrad, Gidrometeoizdat.

Clark, M. P., M. C. Serreze and R. G. Barry. 1996. Characteristics of Arctic Ocean climate based on COADS data, 1980-1993. Geophys. Res. Lett., $23(15), 1953-1956$.

Dingman, S. L., R. G. Barry, G. Weller, C. Benson, E. F. LeDrew and C. W. Goodwin. 1980. Climate, snow cover, microclimate and hydrology. In Brown, J., P. C. Miller, L. L. Tieszen and F. L. Bunnell, eds. An Arctic ecosystem: the coastal tundra at Barrow, Alaska. Stroudsburg, PA, Dowden, Hutchinson and Ross, $30-65$.

Environment Canada. 1993. Forecast almost as good as observations? Climate Perspectives, 15, 11.

Genthon, C. and A. Braun. 1995. ECMWF analyses and predictions of the surface climate of Greenland and Antarctica. J. Climate, 8 (10), 2324-2332.

Gorshkov, S. G., ed. 1983. Arctic Ocean. Vol. 3. World ocean atlas. Oxford, etc., Pergamon Press. U.S.S.R. Navy.

Ivanov, V.V. and V.A. Yankina. 1991. Vodnye resursy Arktiki [Water resources of the Arctic]. Probl. Ark. Antark.,66,118-128. [In Russian.]

Kalnay, E. and 21 others. 1996. The NCEP/NCR 40-year reanalysis project.
Bull. Am. Meteorol. Soc, $77(3), 437-471$.

Kattsov, V. M., T. V. Pavlova and V. A. Govorkova. In press. Heat and water budgets over the northern polar region as estimated from 14 atmospheric general circulation models. In Arctic Climate System Study (ACS1S) Conference, 1994, Göteborg, Sweden. Proceedings. Geneva, World Meteorological Organization. World Climate Programme.

Legates, D, and C. Willmott. 1990. Mean seasonal and spatial variability in gauge-corrected global precipitation. Int. 7. Climatol., $10(2), 111-127$.

Maslanik, J. A., M. C. Serreze and R. G. Barry. 1996. Recent decreases in Arctic summer ice cover and linkages to atmospheric circulation anomalies. Geophys. Res. Lett., 23 (13), 1677-1680.

McCauley, L. L. and M. F. Meicr, eds. 1991. Arctic system science land/atmosphere/ice interactions: a plan for action. Fairbanks, AK, Arctic Research Consortium of the United States (ARCUS).

Serreze, M. C. 1995. Climatological aspects of cyclone development and decay in the Arctic. Atmosphere-Ocean, 33 1), 1- 23.

Serreze, M. C., J. E. Box, R. G. Barry and J. E. Walsh. 1993. Characteristics of Arctic synoptic activity, 1952-1989. Meteorol. Atmos. Phys., 51, 147-164.

Serreze, M. C., R. G. Barry and J. E. Walsh. 1995. Atmospheric water vapor characteristics at $70^{\circ}$ N. J. Climate, $8(4), 719-731$.

Vose, R. S. and 6 others. 1992. The global historical climatology network: long-term monthly temperature, precipitation, sea level pressure, and station pressure data. Oak Ridge, TN, National Laboratory. (Environmental Sciences Division Publication 3912.

Walsh, J. E., W. L. Chapman and T. L. Shy. 1996. Recent decreases of sea level pressure in the central Arctic. 7. Climate, 9 2), 480-486.

Whittaker, L. M. and L. H. Horn. 1984. Northern Hemisphere extratropical cyclone activity for four mid-season months. J. Climatol., 4, 297-310.

Woo, M. -K., R. Heron, P. Marsh and P. Steer. 1983. Comparison of weather station snowfall with winter snow accumulation in High Arctic basins. Atmosphere-Ocean, 21 (3), $312-325$.

Woodruff, S. D., R. J. Slutz, R. L. Jenne and P. M. Steurer. 1987. A comprehensive ocean atmosphere data set. Bull. Am. Meteorol. Soc., 68 (10), 1239 1250.

World Climate Research Programme (WCRP). 1994. Arctic Climate System Study (ACSTS): initial implementation plan. Geneva, World Meteorological Organization Secretariat. (WCRP-85, WMO TD 627.)

Zaucker, T., T. F. Stocker and W. S. Broecker. 1994. Atmospheric freshwater fluxes and their effect on the global thermohaline circulation. f. Geophys. Res., 99 (C6), 12,443-12,457. 